\title{
MÃE ADOLESCENTE CUIDANDO DO FILHO
}

\section{ADOLESCENT MOTHER CARING FOR THEIR CHILD}

Regina Matos*

Anézia Moreira Faria Madeira**

MATOS, R.; MADEIRA, A.M.F. Mãe adolescente cuidando do filho. Rev.Esc.Enf.USP, v.34, n.4, p. 332-8, dez. 2000.

\begin{abstract}
RESUMO
Trata-se de uma pesquisa qualitativa, que teve como objetivo conhecer a percepção das mães adolescentes sobre o cuidar do filho. Como trajetória metodológica, utilizamos da fenomenologia, que como um caminho, um movimento, permitiu-nos apreender a essência do fenômeno a partir dos significados emergidos dos discursos de 7 (sete) sujeitos que participaram da pesquisa. Para as adolescentes cuidar do filho significa: alimentar a criança, fazer a higiene, tratar a doença, promover o sono, dar atenção, dar carinho, promover a recreação e a educação. Estes temas de análise convergiram para 3 (três) categorias abertas: atender as necessidades biológicas da criança, atender as necessidades psíquicas da criança e atender as necessidades sociais da criança.
\end{abstract}

PALAVRAS-CHAVE: Relações mãe-filho. Adolescente. Criança. Cuidado da criança.

\begin{abstract}
This is a qualitative research that had the objective of understanding the perception of adolescent mothers about their child Os care. The phenomenological approach was used to analyze data gathered from 7 mothers. To the adolescent mothers caring for their child means feeding the child, do his/her hygiene, care for his/her illness, promote rest, give attention, give love, give educational support and promote leisure. These themes converge to 3 main cathegories: attend to the biological, psychological and social necessities of the child.
\end{abstract}

KEYWORDS: Mother-child relationhips. Adolescent. Child; Child's care.

\section{INTRODUÇÃO}

Nossa inquietação em saber como as adolescentes cuidavam dos filhos surgiu a partir do momento que participamos, em 1997, juntamente com outros profissionais de saúde, de uma pesquisa encomendada pela Secretaria de Saúde de Belo Horizonte, para avaliar as condições de saúde de crianças consideradas de risco, dentre as quais incluíam-se filhos de mães adolescentes. Os dados eram coletados a partir de fonte secundária, prontuários das crianças, que mostravam peso de nascimento, situação sócio-econômica, intercorrências de saúde, dentre outras variáveis, mas não retratavam a verdadeira experiência do sujeito, devido não haver um contato direto com as adolescentes, impedindo dessa forma conhecer melhor o seu mundo vivido, a interação mãe-filho, no cuidar.
A princípio achávamos que as adolescentes não sabiam cuidar dos filhos, que eram irresponsáveis, inconseqüentes, que seus filhos adoeciam por descuido. Mas, a nossa inserção, a partir de março de 1998, no projeto de assistência intitulado: "Assistência sistematizada à adolescente e seu filho no Centro de Saúde São Paulo", fez com que enxergássemos a mãe adolescente com um outro olhar. Nosso convivio semanal com elas, através das consultas de enfermagem, permitiu que nos aproximássemos cada vez mais delas, e mostrounos que as adolescentes cuidam adequadamente dos filhos, estão preocupadas com a saúde deles e seguem as orientações recebidas durante as consultas.

Ao contrário, VALENZUELA (1987) afirma que um dos riscos da maternidade na adolescência é a

Aluna do $7^{\circ}$ período, do Curso de Enfermagem da EEUFMG; Bolsista do Programa de Aprimoramento Discente (PAD)/UFMG, periodo 1998 .

** Enfermeira, Doutora em Enfermagem, Professora Adjunto da Disciplina Enfermagem Pediátrica da EEUFMG. 
que as adolescentes cuidam adequadamente dos filhos, estão preocupadas com a saúde deles e seguem as orientações recebidas durante as consultas.

Ao contrário, VALENZUELA (1987) afirma que um dos riscos da maternidade na adolescência é a imaturidade emocional e a pouca experiência da adolescente em cuidar do filho.

Segundo SOSA (1988), a maternidade não engloba somente gestação e parto, mas também, os cuidados com a criança. A adolescente tendo superado os riscos da gestação e parto enfrenta a terceira etapa da maternidade, a necessidade do cuidado adequado com o filho, ou seja, criar e guiar a criança até a maturidade. Assim, a preocupação materna em cuidar do filho é expressa em seu comportamento. Essa fase não é fácil, pois a mãe é uma adolescente e não alcançou sua própria maturidade e nem sempre está em condições de satisfazer as necessidades emocionais do seu filho (ROMERO, 1984).

PIZZARRO (1992) pontua que, frente à imaturidade emocional e à pouca experiência em cuidar do filho, a ação de equipes multidisciplinares, abrangendo integralmente mãe e filho durante todas as fases da maternidade, diminui as possiveis complicações inerentes às adolescentes e seus filhos, especialmente nos primeiros meses de vida.

$\mathrm{Na}$ visão desses autores, as adolescentes não têm maturidade suficiente para cuidar da criança, para assumir a responsabilidade de se ter um filho.

Assim, por percebermos a incoerência do que vivenciamos com as adolescentes e o que se veicula nos livros, na mídia, enfim na sociedade como um todo sobre os incovenientes de ser mãe na adolescência, é que optamos por realizar essa pesquisa, no intuito de buscar junto aos sujeitos sua vivência de cuidado do filho. Portanto, pretendemos com esse trabalho conhecer a percepção das mães adolescentes sobre o cuidar do filho.

Acreditamos que, somente através das descrições das adolescentes, poderemos conhecer a experiência delas e compreender como cuidam de seus filhos.

\section{O CAMINHAR METODOLÓGICO}

Essa pesquisa enquadra-se na linha qualitativa, e teve a fenomenologia como trajetória metodológica para se chegar à essência do "Mãe adolescente cuidando do filho".

A fenomenologia foi criada por Edmund Husserl, no séc. XIX, como forma de descrever, explicitar e compreender a essência da existência, dos fenômenos vividos pelo homem.

Fenômeno, nas palavras de BICUDO;
ESPÓSITO (1994), significa o que se mostra, o que se manifesta, o que aparece. E o que se manifesta para a consciência, como resultado de uma interrogação.

Consciência, na fenomenologia, é intencionalidade, é o estar voltado para algo, de forma atentiva. Assim, dirigimo-nos ao fenômeno de forma atentiva, no sentido de apreendê-lo em sua essência.

Segundo BICUDO; ESPÓSITO (1994), a essência do fenômeno, o mostrar-se ou expor à luz, sem obscuridade, não ocorre em um primeiro olhar

o fenômeno, mas paulatinamente dá-se na busca atenta e rigorosa do sujeito que interroga e que procura ver além da aparência, insistindo na procura do característico, do básico, do essencial do fenômeno, a sua verdade (aletheia).

Assim sendo, o cuidar do filho é uma situação existencial, vivenciada intencionalmente pela adolescente, em seu mundo-vida, na interação com o filho. Nosso objetivo, portanto, foi compreender os significados emergidos dessa situação, ou melhor, os aspectos essenciais do fenômeno.

O estudo foi desenvolvido no Centro de Saúde São Paulo, pertencente à Prefeitura Municipal, localizado no Distrito Sanitário Nordeste, da cidade de Belo Horizonte - MG.

As 7 (sete) adolescentes que fizeram parte do estudo, tinham de 17 a 19 anos de idade. Dessas, 4 possuiam o primeiro grau completo, 4 eram solteiras e moravam com os seus pais; 3 eram casadas. Nenhuma trabalhava fora; a maioria morava em favela. Todas as adolescentes tinham apenas 1 filho, e esses eram menores de 1 ano de idade.

Para apreender os aspectos essenciais do fenômeno foram realizadas entrevistas não estruturadas e reuniões de grupo com as adolescentes.

As entrevistas transcorreram durante o mês de Maio de 1998, e tiveram como fio condutor a questão norteadora: "O que é para você cuidar do filho?"; foram agendadas previamente, sendo feitas nos domicílios das adolescentes. Para auxiliar na condução das mesmas, utilizamos o recurso do gravador, com pleno consentimento das participantes. Tão logo terminava cada entrevista, esta era transcrita na íntegra, para não perder nenhum detalhe daquele momento. Assim, gestos, entonação da voz e outros detalhes do encontro eram. relembrados e vivificavam as falas.

A partir do momento que as falas começaram a ficar repetitivas, coincidentes, mostrando alguns sinais de desocultamento do fenômeno, demos por encerrada essa etapa. Com isso, foram realizadas 7 (sete) entrevistas.

As reuniões objetivavam enriquecer ainda mais o fenômeno a partir da percepção dos sujeitos 
Foram realizados 5 (cinco) encontros com as adolescentes, que transcorreram no período de Junho a Outubro de 1998, com duração de aproximadamente 2 (duas) horas. Esses encontros foram conduzidos por dinâmicas de grupo, que abordaram alguns temas referentes aos cuidados com a criança: 1- Alimentação da criança no primeiro ano de vida; 2- Higiene da criança e do ambiente e prevenção de acidentes na infância; 3-Estimulação psicomotora; 4- Como prevenir e tratar das infecções respiratórias agudas; 5Como prevenir e tratar das diarréias agudas.

Os assuntos eram discutidos de forma participativa, isto é, as dinâmicas possibilitaram às adolescentes participarem das discussões de forma espontânea, descontraída, e sentirem sujeitos do processo, participantes ativos, capazes de refletir sobre sua interação com os filhos, no cuidar. Durante esses encontros, procurávamos nos manter na posição de observadoras, conduzindo, às vezes, para o objetivo proposto naquele encontro, mas em momento algum, colocando em evidência o nosso conhecimento. O conhecimento, ao contrário, emergia do grupo, denotando prazer e satisfação das adolescentes por terem oportunidade de falar e de serem ouvidas.

Nesses encontros as adolescentes trocavam experiências, o que as deixavam mais descontraídas, por perceberem que suas dificuldades eram comuns, convergiam para a possibilidade de cuidar melhor dos filhos.

Para proceder a análise compreensiva dos aspectos essenciais emergidos dos discursos das adolescentes, seguimos os momentos sugeridos por MARTINS; BICUDO (1989), ou seja, primeiramente, detivemo-nos na leitura dos discursos do início ao fim, buscando apreender o sentido geral do que estava escrito. No momento em que o sentido foi obtido, voltamos a cada texto e o relemos quantas vezes foram necessárias, a fim de buscar o que era essencial do fenômeno, deixando de lado aquilo que não se configurava como uma característica primordial do mesmo. Assim, chegamos às unidades de significado do fenômeno aqui estudado. Ao imergir nas unidades de significado, foi possivel, por meio de insights, apreender 7 (sete) temáticas: 1Alimentar a criança; 2-Fazer a higiene; 3- Tratar a doença; 4- Promover o sono; 5- Dar atenção; 6-Dar carinho; 7-Promover a recreação e a educação.

Continuando a olhar atentivamente para as temáticas emergidas dos discursos, percebíamos que as mesmas convergiam para 3 (três) categorias abertas (BICUDO; ESPOSITO, 1994): ATENDER AS NECESSIDADES BIOLÓGICAS DA CRIANÇA; ATENDER AS NECESSIDADES

\section{PSIQUICAS DA CRIANÇA e ATENDER AS NECESSIDADES SOCIAIS DA CRIANÇA.}

\section{A CONSTRUÇÃO DOS RESULTADOS}

A construção dos resultados foi feita a partir dos aspectos essenciais do fenômeno, emergidos dos discursos das adolescentes, dos achados das reuniões de grupo e de observações feitas durante as consultas de enfermagem com o binômio mãe/filho.

\section{ATENDER AS NECESSIDADES BIOLÓGICAS DA CRIANÇA}

\section{1- Dar alimento}

Os discursos das adolescentes mostraram-nos que para elas cuidar significa oferecer alimentos às crianças, além de afirmarem que na alimentação a rotina dos horários é de fundamental importância, para se manter a saúde da criança:
"...cuidar é alimentar direitinho...dar o leite na hora certa..." (S1)
"...cuidar...é...dar...alimentação pra ele..."(S2)
"...é não deixar ele passar da hora do almoço... tenho muito cuidado com a alimentação... não dou qualquer coisa. Tudo que dou observo para ver se não dá reação, dou tudo natural, não dou doce...acho que o doce pode estragar os dentinhos dele..." (S3)
"...é dar alimentação na hora certa..." (S4)
"...cuidar é...dar mamadeira..." (S5)
"...cuidar é...dar comida e de mamar na hora certa..." (S6)

A adolescente ao estabelecer a rotina da alimentação do filho, prepara-o para o mundo social, repleto de regras e leis, cujo contato inicial é a própria família. Estabelecer rotinas na educação infantil é importante, porque essas rotinas cotidianas, na concepção de COUTINHO (1978), tornam o mundo da criança mais estável e previsivel. A quebra e modificações bruscas de qualquer ato rotineiro podem trazer um certo prejuízo emocional à saúde da criança.

Segundo LEÃO et al (1998), nos primeiros anos de vida da criança, devido ao intenso metabolismo, crescimento e desenvolvimento acentuados, especialmente do sistema nervoso central, a alimentação assume um papel importante, considerando as altas necessidades nutricionais. 
Deve-se, portanto, estar atento ao equilíbrio adequado entre as substâncias essenciais ao organismo: hidratos de carbono, proteínas, gorduras, vitaminas e sais minerais. A satisfação das necessidades nutricionais é um cuidado indispensável para o crescimento adequado da criança.

Para as adolescentes, a alimentação da criança deve abranger não apenas o leite natural, como também a oferta de outros alimentos. Durante a reunião de grupo, onde discutiu-se o tema alimentação da criança no primeiro ano de vida, utilizando-se da dinâmica "batata quente", as adolescentes relataram que: "o leite de peito é importante, porque protege contra as doenças", "o leite de peito é bom, porque faz a criança ficar forte, desenvolver direitinho", "quando a criança fica sem alimentar ela fica magrinha, desnutrida", "se ele não quer uma coisa eu dou outra, eu só não consigo ver ela sem comer".

As adolescentes mostram em suas falas um certo conhecimento sobre a importância de se alimentar os filhos, seguindo uma rotina préestabelecida, além de garantir-lhes a qualidade da alimentação. Assim, tendo o cuidado de alimentá-los adequadamente estarão contribuindo para o crescimento satisfatório dos filhos. Haja vista, que durante o acompanhamento do crescimento e desenvolvimento, através da consulta de enfermagem nenhuma criança ficou abaixo do percentil 10 , da curva de crescimento, ou seja, não houve nenhum caso de desnutrição.

\section{2 - Fazer a higiene}

Para as adolescentes cuidar do filho é:

"...dar o banho na hora certa...trocar a fralda dele..." (S1)

"...dar higiene pra ele..." (S2)

"...deitar ele sempre em lugares limpos...não deixar ele em chão sujo...ter o máximo de higiene, cortar bem as unhas, limpar as orelhas, lavar e passar bem direitinho as roupas. Ter tudo dele separado: sabonete, toalha, pratinho, colher..." (S3)

$" \therefore$ fazer a higiene dela direitinho...é o que eu faço: banho, higiene..." (S4)

"...não deixar ela suja...dar banho no mesmo horário...quando ela acordar dar outro banho nela..." (S5)

"...dar banho..." (S6)
FERREIRA (1984) afirma que a higiene é a arte de conservar a saúde, através da adoção de medidas de limpeza.

Segundo as adolescentes, cuidar é basicamente fazer a higiene do corpo das crianças, por meio de uma rotina diária, do fazer perfeito, direito, que implica em dar o banho, trocar as fraldas, cortar as unhas, e também fazer higiene dos pertences dos filhos.

Durante a discussão com as adolescentes do tema: higiene da criança, utilizando-nos de cartilha contendo as principais medidas para a higiene do filho, pudemos perceber que a fervura dos utensilios, filtração da água e outras medidas de higiene eram utilizadas pelas adolescentes. Haviam dúvidas acerca da limpeza adequada da genitália, especialmente a feminina, e também da idade em que se inicia a escovação dentária. Apesar disso, durante as consultas para o acompanhamento do crescimento e desenvolvimento da criança, não houve casos de infecção urinária e as crianças sempre se apresentavam em condições satisfatórias de higiene corporal.

A higiene enquanto medida de prevenção de doenças envolve não somente o corpo, mas também o ambiente onde o indivíduo se insere, uma vez que ambos estão em constante interação. Assim, no processo de promoção da saúde da criança, higiene corporal e ambiental são indissociáveis.

A exemplo disso, LEÃO et al (1998) afirmam que no diagnóstico das infecções respiratórias agudas, é preciso que se leve em conta as condições ambientais, tais como característica da moradia e número de pessoas que nela residem, presença de mofo e outros alérgenos, sobretudo poeira doméstica, uso recente de tintas e inseticidas, familiares tabagistas, exposição ao sol e ainda o estado de saúde das pessoas que convivem com a criança. Ressaltam que $90 \%$ das infecções respiratórias agudas são, primariamente, não bacterianas. Os indices de morbidade por infecção respiratória relacionam-se com a baixa temperatura ambiental. Uma das prováveis explicações para isso reside na tendência de se permanecer no interior das residências nos períodos mais frios e ou úmidos, quando o ambiente fechado e a ventilação reduzida facilitam a propagação de infecções e sensibilização a fatores alergênicos (poeira domiciliar e mofo, por exemplo).

Dentre as intercorrências de saúde encontradas nos filhos das adolescentes, por ocasião das consultas de enfermagem, as doenças respiratórias mostraram forte relação com as condições insalubres dos domícilios, presença de tapetes, cortinas, presença de animais domésticos e fumantes nas moradias - informações relatadas pelas adolescentes. 


\section{3 - Estar atenta à saúde do filho}

A atenção à saúde do filho aflorou dos discursos como um dos aspectos essenciais do fenômeno, apontado pelas adolescentes como uma das maneiras de cuidar do filho:

"...cuidar é proteger ele, cuidar da saúde dele..."(S2)

"...cuida é...qualquer coisinha levar ao médico..." (SI)

"..levar no médico sempre que precisar..." (S3)

...cuidar é...quando tiver doente levar no médico... dar os remédios direitinho quando a médica passá..:"(S6)

Cuidar, na percepção das adolescentes, é estar atenta à saúde do filho, levando ao médico e administrando os medicamentos prescritos. Culturalmente, o médico é tido pela sociedade como aquele indivíduo que polariza todo conhecimento acerca das doenças. Pressupõe-se que o mesmo possui a "fórmula mágica" para salvaguardar a saúde da população.

A promoção da saúde inclui entre várias medidas a prevenção e o combate às doenças. Segundo LEAO et al (1998), as principais doenças causadoras de morte na infância, nos países subdesenvolvidos são: diarréia, doenças imunopreveniveis e doenças respiratórias.

Doenças diarréicas e infecções das vias aéreas superiores são queixas freqüentes das mães adolescentes por ocasião das consultas de enfermagem. As doenças diarréicas são preveníveis através de medidas de higiene e saneamento básico, e o seu tratamento é possivel pelas técnicas de reidratação oral (sais de reidratação oral e soro caseiro), que são medidas simplificadas, não traumáticas e de baixo custo para a população. Já a prevenção das doenças respiratórias envolve mudanças na estrutura das moradias e é dificultada nos centros urbanos pelas próprias condições de poluição a que estão expostos os indivíduos. Além disso, o tratamento das infecções respiratórias envolve o uso de terapêutica adequada, tornando o seu custo mais oneroso.

Durante a discussão com as adolescentes dos temas: como prevenir e tratar das doenças diarréicas e das infecções respiratórias agudas, através de álbum seriado, pudemos perceber que as infeccões respiratórias são mais temidas pelas mães que as doenças diarréicas, talvez, por se sentirem impossibilitadas para cuidar da criança, já que a resolubilidade depende da melhoria das condições sócio econômicas. No entanto, para o tratamento das diarréias elas utilizam medidas mais simplificadas, como soro caseiro e sais de reidratação oral, além de alimentos obstipantes, relatados por elas durante a reunião.

\section{4 - Promover o sono}

Para as mães adolescentes cuidar é promover o sono dos filhos:

"é... não atrasar na hora de dormir..." (S3)

"...cuidar é...deixar ela dormir..." (S5)

O sono é apontado pelas adolescentes como uma necessidade básica da criança, portanto, deve se respeitar o seu horário, e a individualidade do filho. Segundo FERREIRA (1984), o sono é o estado de repouso normal e periódico do homem e de outros animais superiores. Através do sono há reposição das energias dissipadas durante as atividades diárias.

O período necessário de repouso varia de indivíduo para indivíduo, e a sua duração e qualidade guardam uma relação direta com o ambiente onde a criança vive. O excesso de ruídos e estímulos pode prejudicar o padrão normal de sono para aquela determinada idade, além de trazer transtornos na esfera emocional, como irritabilidade e perda do apetite. Além disso, o sono é um elemento importante para o crescimento da criança, uma vez que um dos hormônios responsáveis por ele, a somatotrofina, é secretado durante o sono (WHALEY;WONG, 1985).

\section{II - ATENDERAS NECESSIDADES PSÍQUICAS DA CRIANÇA}

\section{5 - Dar carinho}

A questão do carinho na relação com o filho emergiu nas falas das adolescentes como forma de cuidar:

"...cuidar é, dar sempre carinho..." (S1)

"...cuidar...passar o meu amor pra ele..." (S2)

"...tratar dele(a) bem..." (S4, S6)

"...tem que ter...carinho..." (S7)

A necessidade emocional mais importante para a criança é a de ser e sentir-se amada. O amor deve ser transmitido através de palavras e ações. Quando seguras desse amor, as crianças são capazes de superar as crises normais associadas ao desenvolvimento, bem como as crises inesperadas: doenças e perdas (WHALEY; WONG, 1985).

A mãe adolescente se relaciona com o filho, carinhosamente, através do cuidar. É como ‘...um harmonioso nexo nas reações de ambos, semelhante à uma dança sincronizada entre mãe e filho" (KLAUS; KENNEL, 1978). 


\section{6 - Dar atenção}

Os discursos das mães adolescentes mostraram-nos que cuidar do filho significa dar atenção:

"...cuidar...é dar atenção pra ele, ficar sempre junto com ele, vendo as necessidades dele...porque toda hora a gente tem que ta de cima...pra o que ele precisa..." (S1)

":..só de olhar pra mim eu sei o que ele tem. Se percebo dor, peito cheio, tosse, não quer comer. Eu sei quando ele não tá legal. Tudo dele eu sei..." (S3)

As adolescentes colocam que tem que ficar a postos, sempre atentas às solicitudes dos filhos, o que implica em dedicação. Elas lêem no corpo do filho, através de seus sinais, o que está acontecendo com ele, se se trata de alguma doença ou de outro problema qualquer. A convivência cotidiana com o filho faz com que elas vão conhecendo-o cada vez mais, se sentindo-se experientes para cuidar dele: "..é bom. É uma experiência nova que eu nunca tive... "(S2)

A atenção/dedicação está intimamente ligada ao amor materno. É através do toque, da voz, do carinho que a relação mãe-filho vai se construindo e se cristalizando, tornando os vínculos afetivos mais fortes entre eles.

Assim, além do amor, a mãe fornece ao filho a segurança. Através da atenção contínua, da rotina cotidiana, as mães são capazes de identificar e agir frente às necessidades do filho, expressadas por seu corpo (WHALEY; WONG, 1985).

Para as adolescentes que fizeram parte do estudo, no processo de cuidar, a atenção é de fundamental importância, pois permite identificar as necessidades da criança, conhecê-la, uma vez que a mãe está em vigília constante do filho.

Cuidar em sua expressão latina significa zelar, relacionar com algo, e Heidegger denomina o cuidar como a estrutura fundamental do ser-aí, do humano. O cuidado ou "cura" define o homem como ser-nomundo no seu existir, no seu estar-lançado no mundo, na ocupação com os entes que vêm ao seu encontro: "Todos os comportamentos e atitudes do homem são dotados de cura e guiados por uma dedicação" (HEIDEGGER, 1989: 265).

$\mathrm{Na}$ reunião onde discutiu-se o tema estimulação psicomotora, as adolescentes expressaram, por meio de desenhos, as características do desenvolvimento do filho em suas diferentes idades. Percebemos, nessa expressividade, que elas estavam atentas a cada gesto/ação diferente desenvolvido por seus filhos. Além disso, durante as consultas de enfermagem elas sempre perguntavam sobre os gestos/ações normais e anormais nas diferentes faixas etárias e as comparavam com as de seus filhos demonstrando, assim, que elas não estavam preocupadas apenas com sinais de doenças mas, também, com os parâmetros evolutivos do desenvolvimento infantil.

\section{III - ATENDER AS NECESSIDADES SOCIAIS DA CRIANÇA}

\section{7 - Promover a recreação e a educação}

Apreendemos dos discursos das mães adolescentes que cuidar significa para elas promover a recreação e a educação do filho, como expressado em seus relatos:

"...pra mim é assim...passeio, de vez em quando levo para divertir..." (S4)

"...cuidar é...dar educação pra ele, para ele aprender tudo da vida..." (S2)

A recreação faz parte do mundo social da criança. Através da atividade lúdica, representada pelo brinquedo e contato com a natureza, a criança expande sua relação com o mundo e vai se descobrindo paulatinamente. O brinquedo, ao mesmo tempo que socializa a criança, faz com que_ ela extravase energias, se distraia, se torne criativa e aprimore cada vez mais o seu desenvolvimento.

Segundo a adolescente S2, cuidar é dar educação para o filho, para que ele possa ter um mundo melhor, compactuando dessa forma com a definição de FERREIRA (1984), de que a educação é o desenvolvimento físico, intelectual e moral do indivíduo, o que o torna um ser completo, apto para "aprender tudo da vida".

Portanto, o cuidar não se restringe apenas às necessidades básicas da criança, ele transcende as solicitações do corpo físico para habitar um mundo social, no qual a figura materna tem um papel preponderante, que na verdade significa que ela tem que educar o filho.

\section{CONSIDERAÇÕES FINAIS}

As adolescentes mostraram em suas falas que a interação com o filho se converge para um cuidar pautado no atendimento das necessidades humanas básicas (biológicas, psíquicas e sociais).

Para as adolescentes atender às necessidades biológicas significa dar o alimento, fazer a higiene da criança, tratar a doença e promover o sono. $O$ cuidar, direcionado para as necessidades psicossociais, significa dar carinho, dar atenção, educar a criança e promover a recreação. O cuidado 
biológico necessita de uma rotina, onde a freqüência e o ritmo devem ser respeitados. Já o cuidado psicossocial se caracteriza como um processo contínuo, de constante vigília materna, mostrando dessa forma, que o cuidar do filho é dificil e agradável ao mesmo tempo. Dificil por ser contínuo, ininterrupto, e agradável por possibilitar prazer, satisfação, crescimento e auto-realização.

As categorias afloradas dos discursos mostraram as peculiaridades do cuidar do filho para esse grupo de adolescentes, constituindo, portanto, numa verdade para elas. E uma maneira de viverem esse fenômeno com todas as suas particularidades: cultura, lugar, tempo, história, dimensão social e econômica. É a facticidade dessas adolescentes que é colocada à mostra. Portanto, são generalidades do grupo, aspectos comuns entre as adolescentes, sujeitos da pesquisa, que iluminam algumas facetas do fenômeno, e não generalizações, o que significa transpor os aspectos essenciais aflorados aqui para toda e qualquer mãe adolescente no cuidado com o filho.

Os significados emergidos nesta pesquisa confirmam a incoerência existente entre o discurso dos profissionais de saúde e da mídia sobre os inconvenientes de ser mãe na adolescência e a prática real do cuidar do filho pelas adolescentes. É preciso, portanto, desvestirmo-nos de preconceitos em relação às mães adolescentes e passarmos a enxergá-las com um novo olhar, já que a maneira como cuidam do filho não difere daquela da mãe adulta, como ficou patente

\section{6 - REFERENCIAS BIBLIOGRÁFICAS}

BICUDO, M. A. V.; ESPÓSITO, V. H. C. Pesquisa qualitativa em educação. São Paulo, UNIMEP, 1994.

COUtinho, M. T. da C. Psicologia da criança - da fase prénatal aos 12 anos. 2.ed. Belo Horizonte, Interlivros, 1978.

FERREIRA, A. B H. Novo dicionário da língua portuguesa. Rio de Janeiro, Nova Fronteira, 1984.

HEIDEGGER, M. Ser e tempo: Parte I. 3.ed. Petrópolis, Vozes, 1989.

KLAUS, M. H.; KENNELL, J. H. La relación madre hijo: impacto de la separación o pérdida prematura en el desarrollo de la familia. Buenos Aires, Panamericana, 1978.

LEÃO, E. et al. Pediatria ambulatorial. 4.ed. Belo Horizonte, Coopmed, 1998

MARTINS, J; BICUDO, M. A. V. Pesquisa qualitativa em psicologia: fundamentos e recursos básicos. São Paulo, Moraes, 1989.

PIZZARRO, A. R. Factores de riesgo en el crescimento del hijo de madre adolescente en Punta Arenas. Rev. Chilena Ped., v.63, n.3, p. $153-8,1992$.

ROMERO, M. I. et al. Característica del primer ano de vida de hijos de madres dolescentes: un estudo descriptivo de segmiento. Cuad. Med. Soc., v.25, n.3, p.124-9, 1984.

SOSA, R. I. P. El hijo lactente de madre adolescente. Anales Fac. Ciências Méd. Univ. Nac. Assunción, v.20, n.1, p.151-68, 1988 .

VALENZUELA, M. S. Primer ano de vida en hijos de adolescentes. Boletin Hosp. San Juan Dios, v.34, n.2, p.815, 1987.

WHALEY, L. F.; WONG, D. C. Enfermagem pediátrica: elementos essenciais à intervenção efetiva. 2.ed. Rio de Janeiro, Guanabara, 1985. 